\title{
Writing Energy Economics Research for Impact
}

\author{
Michael Dowling, ${ }^{a}$ Helmi Hammami, ${ }^{b}$ Dima Tawil, ${ }^{c}$ and Ousayna Zreik ${ }^{d}$
}

\begin{abstract}
We explore the drivers of impact for energy economics research based on an analysis of citations generated by The Energy Journal articles. The focus is on nontopic generators of impact. Our regression analysis shows that these non-topic measures can explain a substantial proportion (about 20\%) of variation in future citations. We apply these findings, integrated with prior research on effective economics writing style, to recommend how energy economics articles should be written to increase their impact. These recommendations center particularly around the importance of initial article information provided to the reader and article structure.
\end{abstract}

Keywords: The Energy Journal, Impact, Citations, Readability, Scientometrics

https://doi.org/10.5547/01956574.42.3.mdow

\section{UNDERSTANDING ENERGY IMPACT}

Energy economics researchers, like all researchers, are motivated to generate impact from their research. Impact can be defined both broadly in terms of the beneficial contribution of research to society (Penfield et al., 2014), as well as more narrowly in terms of the contribution the research makes to the development of knowledge within a discipline (Li, Liao and Yen, 2013). Our focus in this study is on the latter definition and we measure research impact, similar to Li, Liao and Yen (2013), through citations to a published article. We investigate the non-topic drivers that contribute to these future citations and interpret our findings to advise authors of energy economics articles on effective writing style and article structure.

Citations to an article generally demonstrate that the research has stimulated theoretical, empirical, or policy discussion in future research. As a result, citations to a researcher's body of work are important in career promotion processes as part of an assessment of research contribution (Reinstein et al., 2011). They also act as a form of intrinsic motivation by showing the researcher they are contributing to the development of knowledge in their field.

Researchers are, therefore, motivated to produce research that generates citations. Primarily this involves creating contributions that advance knowledge and understanding. But individual articles must also attract the attention of researchers who might build on their ideas. Consider a reasonable peer group of reputable sources for energy economics research comprising The Energy Journal, Energy Economics, and the Journal of Environmental Economics and Management. There were over 2,000 articles published by just these three journals in the last five years. There is a

a Corresponding author. Department of Finance and AI Business Research Centre, Rennes School of Business, 2 rue Robert d'Arbrissel, 35065 Rennes, France. Send correspondence to Rennes School of Business, 2 rue Robert d'Arbrissel, 35065 Rennes, France. E-mail: michael.dowling@rennes-sb.com.

b Rennes School of Business, 2 rue Robert d'Arbrissel, 35065 Rennes, France.

c Rennes School of Business, 2 rue Robert d'Arbrissel, 35065 Rennes, France.

d Department of Insurance and Banking, Faculty of Economics, Damascus University, Damascus, Syria. 
crowded marketplace of energy economics ideas, and new research somehow needs to attract the attention of researchers who will cite that research to build their research arguments. The working hypothesis of this study, therefore, argues that better written and structured energy economics articles will be more likely to be noticed and ultimately cited in a busy research environment characterized by limited researcher attention.

Having one's research accepted by journals with a high reputation is one means of generating attention and signaling the importance and relevance of the research. The case in point of this study is energy economics research published in The Energy Journal. Our study sample shows that articles in The Energy Journal generated an average of 11 citations in the five years after publication. The journal is ranked in the first quartile of economics journals in the ISI Journal Citation Report. It is one of the two joint-top field journals for energy and environmental economics from a list of 61 ranked journals in the 'Agricultural, Environmental and Energy Economics' category of the Centre National de la Recherche Scientifique (CNRS) in France. It holds similarly elevated rankings in other national research journal ranking systems. However, not every article published in the journal has an equal impact, a feature in common with all journals. The median number of citations is less than the average at 7 cites per article. Thirty percent of articles receive 3 or fewer citations, and the top 10 percent of the most cited articles account for 37 percent of all citations. A sizable minority of articles are therefore not particularly impactful, and a small number of articles deliver an out-sized influence.

In this study, we systematically analyze articles published in The Energy Journal to show how non-topic factors can influence future citations in energy economics. We show, using regressions of citations on non-topic factors in articles published in The Energy Journal between 1996 and 2013, that about 20 percent of the variation in future citations is related to these measures. Our findings, therefore, cover an important range of factors in determining research impact: writing style and article structure matters. To carry out our study, we build on the scientometrics literature to develop measures of writing and structural choices in research publications. Scientometrics is a research field that involves the analysis of scientific literature, including determining important factors in generating research impact. The initial focus is on the first information that a potential reader sees when considering whether to read an article (title, abstract, topic). A second focus is on the structural choices in framing and writing the article itself (writing style, presentation, and references). The final focus is on author characteristics. While our study has a statistical analysis as its foundation, we present the findings in the form of advice for future writers.

In designing this study, we are conscious that an important overall finding of the scientometrics literature is that there is no one size fits all approach that works in writing impactful research (Tahamtan, Afshar and Ahamdzadeh, 2016). For example, papers in sociology with short titles receive more citations than papers with long titles, while the opposite is true of medical research (van Wesel, Wyatt and ten Haaf, 2014). There also tend to be particular patterns of conformity that signal belonging to a research group (Walker, 2010), such as structuring research in a certain fashion or citing from an informally agreed set of sources. Thus, what works in broad scientometrics with its study of very large corpora of articles, does not necessarily work at the individual journal level. Our research, therefore, draws from the broad scientometrics perspective but allows a specific understanding of how writing decisions in energy economics research influences future citations.

Our study is related to popular guidance on the importance of good writing in economics, most notably by McCloskey $(1985,2019)$, and in energy science (Weiss and Newman, 2011). Our contribution is the integration of this guidance through a quantitative scientometrics investigation of the relationship between article features and future citations. This is the first study to carry out such a quantitative investigation in energy economics, and the most comprehensive study of its kind in the broader economics field. Doing so results in more qualified guidance based on empirics com- 
pared to prior wide-ranging economics writing guides, and richer guidance personalized to energy economics than the scientometric studies. Our methodological approach is quite close to Dowling, Hammami and Zreik (2018), who analyze the impact of article features on citations for Economics Letters articles, but we significantly expand on that study, which just examined three of the 19 article features that this study examines. As the ultimate aim of this study is to highlight the features of writing and structure that influence impact, we write up our results in the form of a writing guide, integrating the relevant findings in the justification for the advice. The next section describes the data and testing approach, and the following section presents the findings and guidance.

\section{EMPIRICAL APPROACH}

Using Scopus, we identify all articles published in The Energy Journal from 1996 to 2013. Information in Scopus was significantly incomplete before 1996 and 2013 is the latest publication year possible because citations up to five years after publication (up to the end of 2018) is our main dependent variable. We only include documents of type 'articles,' thus excluding other document types that the journal occasionally publishes such as 'reviews' and 'editorials.' Excluding also articles with incomplete information for at least one important variable, we are left with a final sample of 504 articles.

The main dependent variable (DV), 5-year Citations, includes all Scopus citations to an article except self-citations, in the first five years following publication. On average, there are 10.6 citations per article, with a median of seven citations. There is also a notable skew in the citation distribution, with the top $10 \%$ of articles contributing $37 \%$ of total citations. We need to account for this skewed distribution in our testing, so we calculate the DV as the inverse hyperbolic sine (asinh) of citations (Card and DellaVigna, 2017; Dowling, Hammami and Zreik, 2018). We also construct some additional DVs. To test shorter time-period citations, we use 3-year Citations, and for a longer time period, we construct 10-year Citations. We also test, using a dummy variable construction, whether the top 25 percent of most cited articles have particular features that are related to citation success.

The testing approach is OLS regressions of the asinh-transformed counts of citations DVs and probit regressions of dummy DVs coded 1 if an article is among the top 25 percent most-cited articles and 0 otherwise. All independent variables (IVs), described below, are included in the regressions. As the range of IVs is quite large, we apply general-to-specific (GETS) modeling (Campos, Ericsson and Hendry, 2005; Hansen, 1996) to arrive at a more parsimonious model through implementing the Stata genspec package of Clarke (2014). Lastly, we calculate the elasticities of significant independent variables to determine practical importance.

Our IVs are generally measures of the non-topic features of an article, except for one control measure of the article topic. We formally define all variables in Table 1. We focus initially on the first decision point that a potential reader reaches; assessing the title, topic, and abstract of an article to decide if the article is worth reading. Readers can view this initial information on The Energy Journal website (or other similar websites) before accessing the article itself. We measure the topic based on the first JEL code of an article (Topic_JEL) as a dummy variable that equals 1 if the JEL code begins with 'Q4' (Energy economics topics) to divide articles into those that fit with the core focus of the journal and those a bit removed from the core objectives. For the title, we generate measures of title length (Title_Length) and whether there is a question mark (Title_Question) or colon (Title_Colon) in the title construction. In the abstract, we measure the length of the abstract (Abs_Length) and readability complexity (Abs_Readability) using the well-established Gunning Fog Index (Bailin and Grafstein, 2016) which we calculate as: 


$$
F O G=0.4\left[\left(\frac{\text { words }}{\text { sentences }}\right)+100\left(\frac{\text { complex_words }}{\text { words }}\right)\right] \text {, }
$$

where a complex word is one with three or more syllables, excluding common endings.

We next explore the structural and readability features of the article itself. Similar to the measures for abstracts, we measure article length (Paper_Length) and readability complexity (Paper_Readability). Two further readability measures are a count of commas (Paper_Commas) in an article to proxy for sentence complexity and whether the article is written in an active voice as measured by use of we (Paper_Active). Both of these measures are scaled by page count as they are naturally highly correlated with the total number of words in an article. We proxy for whether a paper is theoretical or empirical by including a dummy variable that equals 1 if an article contains two or more tables (Tables) as theoretical articles will have low numbers of tables. We also count figures and charts (Figures) to examine the benefit of these visual interpretations in generating impact.

Three variables measure the references in an article. The first is a simple count of references scaled by the number of pages in the article (Ref_Count). The second variable is the proportion of references cited in an article that is from the previous five years (Ref_Recent). The third variable is the proportion of references from the ten most popular peer journals (including The

\section{Table 1: Variable definitions}

\begin{tabular}{|c|c|}
\hline Variable & Description \\
\hline 5-year Citations & $\begin{array}{l}\text { Dependent variable: citations to an The Energy Journal article in the five years following publication } \\
\text { excluding self-citations. Two measures: (1) Inverse hyperbolic sine (asinh) transformation of all } \\
\text { citations, and (2) Dummy variable equal to } 1 \text { for papers at/above top } 25 \text { percent of most cited } \\
\text { articles }\end{array}$ \\
\hline 3-year Citations & Same as 5-year Citations except three year citation window \\
\hline 10-year Citations & Same as 5-year Citations except ten year citation window \\
\hline Topic_JEL & Dummy variable equal to 1 if JEL code for article begins with 'Q4'-energy economics topics \\
\hline Title_Length & Word count of article title \\
\hline Title_Question & Dummy variable equal to 1 if title contains a question mark \\
\hline Title_Colon & Dummy variable equal to 1 if title contains a colon \\
\hline Abs_Length & Word count of article abstract \\
\hline Abs_Readability & Gunning Fog Index of readability complexity of abstract as defined in Section 2 \\
\hline Paper_Length & Page count of article \\
\hline Paper_Readability & Gunning Fog Index of readability complexity of article as defined in Section 2 \\
\hline Paper_Commas & Number of commas in article scaled by number of pages \\
\hline Paper_Active & Number of uses of 'we' active voice in article scaled by number of pages \\
\hline Tables & Dummy variable equal to 1 if article contains two or more tables \\
\hline Figures & Dummy variable equal to 1 if article contains two or more figures \\
\hline Ref_Count & Count of references cited in an article scaled by number of pages \\
\hline Ref_Recent & $\begin{array}{l}\text { Percentage of references cited in an article that were published in the five years prior to the } \\
\text { publication year of the article }\end{array}$ \\
\hline Ref_Peer & $\begin{array}{l}\text { Percentage of references in an article that cite papers from the ten most common journal citation } \\
\text { sources for The Energy Journal. Journals are, in order from most popular: (1) The Energy Journal, } \\
\text { (2) Energy Economics, (3) Energy Policy, (4) Econometrica, (5) American Economic Review, } \\
\text { (6) Journal of Econometrics, (7) Journal of Political Economy, (8) Journal of Environmental } \\
\text { Economics and Management, (9) Journal of Regulatory Economics, and (10) Review of } \\
\text { Economics and Statistics }\end{array}$ \\
\hline Author_Count & Count of number of authors of an article \\
\hline Author_Cites & $\begin{array}{l}\text { Average citations for all authors of an article up to the year before the year of article publication } \\
\text { (with asinh transformation) }\end{array}$ \\
\hline Author_RankInstit & $\begin{array}{l}\text { Highest ranked author institution based on Shanghai Academic Ranking of World Universities } \\
\text { (ARWU) at time of publication. Articles before } 2003 \text { ranked on } 2003 \text { ARWU. Categorical } \\
\text { variable: } 0 \text { 'unranked', } 1 \text { '200-500 rank', 2 '50-199 rank', 3 '1-49 rank' }\end{array}$ \\
\hline Periods & Dummy variable equal to 1 for articles published from 2004 onwards \\
\hline
\end{tabular}


Energy Journal; see Table 1 for the full list) cited as references in all journal articles over the sample period (Ref_Peer).

The last group of variables is related to the authors of articles. We include a count of authors (Author_Count), the average citations of an articles' authors up to the year before publishing their article (Author_Cites; this is asinh-transformed similar to the main DV), and the rank of the best-ranked institutional affiliation among the authors of the article (Author_RankInstit). We use the Shanghai Academic Ranking of World Universities (ARWU) ranking of the top 500 universities for this purpose. The ARWU ranking is updated each year, so we use the institutional ranking in the year of article publication except for articles published before 2003, where we use the 2003 ARWU ranking as this is the earliest available ranking. We divide the institutional rankings into four categories: institutions ranked 1-49th, ranked 50-199th, ranked 200-500th, and unranked. A significant number of authors in the last category are from outside of traditional academia. The top rank is chosen over the average author rank, as this is most visible to readers. We also include a period dummy to control for time effects, which is equal to 1 for the period 2004-2013 due to a clear visual break in citations after 2003 (see Figure 1 (top figure)). The period dummy is preferred to yearly dummies as there is no obvious rationale for using yearly dummies.

\section{GUIDANCE ON WRITING WITH IMPACT IN ENERGY ECONOMICS}

Table 2 provides descriptive statistics and pairwise correlations. We see from this table, and from Variance Inflation Factor inspection, that there is no problem with correlations. Figures 1,2 , and 3 provide a visual exploration of the descriptive features of the dataset. Table 3 reports the overall testing, and Table 4 contains additional testing using GETS modeling and analysis of elasticities. In the following guidance, we integrate the descriptive exploration, formal testing, and prior research findings to propose best practice on writing impactful energy economics research.

We first discuss some broad overall findings. From the descriptive statistics in Table 2, we see the average three-year citations per article are 5; for five years, it is 11; and for ten years, it is 24 . In Figure 1 (top figure) we see a strong upward trend in citations per paper over time; a trend which has been incorporated in our testing. The tests reported in Table 3 contain the overall models for asinh-transformed citation counts in columns 1-3, and for the top 25\% most-cited articles dummy variable in columns $4-6$. The asinh models show explanatory power of about $20 \%$, with the mostcited articles models reasonably comparable. From the significance levels of IVs, it is clear that just a few of the variables drive this explanatory power. We confirm this with the GETS modeling in Table 4 where just 5-7 variables are retained in the reduced form models.

\subsection{First impressions}

The first set of information that a potential reader of an article sees on The Energy Journal website (or when searching for an article through Google Scholar or other article databases) is the title, abstract, and topic of the article. We concentrate here on the title and abstract as the readability measures, but our findings in Table 3 show no impact of the topic dummy based on JEL codes. Other (unreported) variations of this variable also show no significance.

\subsubsection{Titles}

Titles of articles are (surprisingly) important for impact. Previous research on title length has shown higher citations for shorter titles (Hudson, 2016), although, as noted in the introduction, there can be discipline-specific differences. This is possibly related to articles with longer titles be- 
Figure 1: Top figure: Average article 5-year citations by publication year. Citations are raw citation counts. Bottom figure: Average Gunning Fog Index abstract readability scores by publication year. Y-axis starts at $\mathbf{1 3}$ as the score measures readability based on schooling years and 13 is the first year of university.

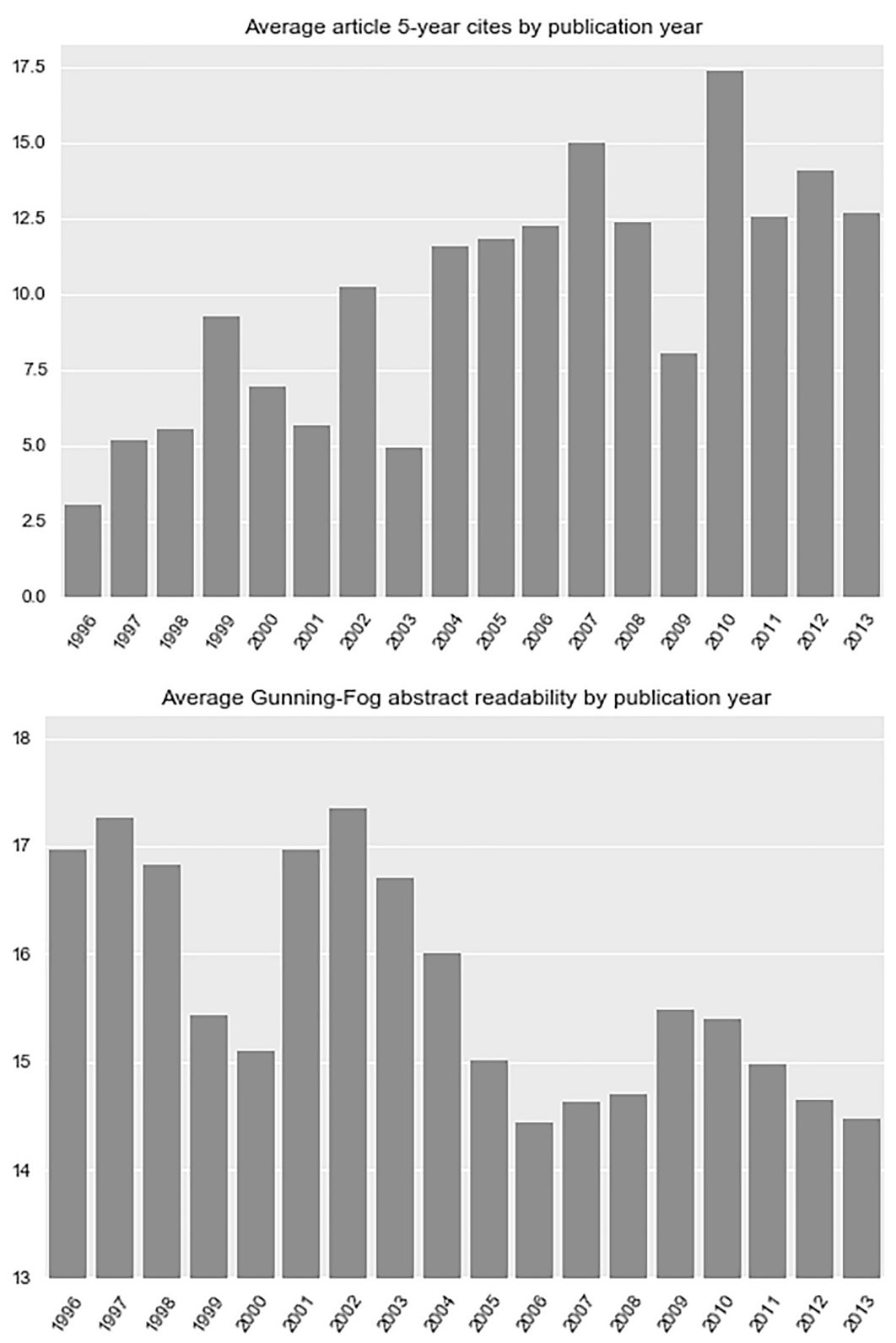

ing less likely to be downloaded (Jamali and Nikzad, 2011). Posing the title as a question increases citations (Costello et al., 2019), while colons in a title can reduce citations, although often this is because the use of colons is a proxy for longer title length (Jamali and Nikzad, 2011).

In our sample, the average title is 11 words, $12 \%$ of titles contain a question mark, and $41 \%$ a colon. The results in Table 3 show a negative relationship with title length. Titles with a question mark have a short-to-medium term positive impact on citations. Different from the prior findings, 
Table 2: Variable descriptive statistics

\begin{tabular}{lccccc}
\hline & Mean & Std.Dev & Min & Max & Pairwise.Corrs \\
\hline 5-yearCitations & 10.61 & 12.99 & 0.00 & 123.00 & 1.0000 \\
3-year Citations & 5.27 & 6.55 & 0.00 & 59.00 & 320.00 \\
10-year Citations & 23.72 & 32.32 & 0.00 & 1.00 & 0.0600 \\
Topic_JEL & 0.57 & 0.50 & 0.00 & 21.00 & -0.0493 \\
Title_Length & 10.62 & 3.57 & 3.00 & 1.00 & 0.0897 \\
Title_Question & 0.12 & 0.33 & 0.00 & 1.00 & 0.0557 \\
Title_Colon & 0.41 & 0.50 & 0.00 & 275.00 & 0.0925 \\
Abs_Length & 145.80 & 36.40 & 46.00 & 35.62 & -0.0896 \\
Abs_Readability & 15.44 & 2.71 & 9.07 & 53.00 & 0.1800 \\
Paper_Length & 22.89 & 7.12 & 10.00 & 18.02 & 0.0505 \\
Paper_Readability & 12.57 & 1.42 & 8.07 & 57.65 & 0.0482 \\
Paper_Commas & 22.80 & 5.76 & 0.12 & 1.00 & 0.1062 \\
Paper_Active & 1.58 & 1.27 & 0.00 & 1.00 & 0.0387 \\
Tables & 0.85 & 0.35 & 0.00 & 5.07 & 0.0530 \\
Figures & 0.71 & 0.46 & 0.00 & 1.00 & 0.1091 \\
Ref_Count & 1.31 & 0.67 & 0.15 & 1.00 & 0.1734 \\
Ref_Recent & 0.47 & 0.23 & 0.00 & 16.00 & 0.0518 \\
Ref_Peer & 0.25 & 0.16 & 0.00 & 0.1660 \\
Author_Count & 2.18 & 1.25 & 1.00 & 9132.00 & 0.0262 \\
Author_Cites & 164.30 & 477.10 & 0.00 & 1.00 & -0.0313 \\
Author_RankInstit: & & & & 1.00 & -0.0963 \\
: Unranked & 0.38 & 0.49 & 0.00 & 1.00 & -0.0182 \\
: 200-500th & 0.17 & 0.38 & 0.00 & 0.1344 \\
$:$ 50-<200th & 0.19 & 0.40 & 0.00 & & \\
: 1-<50th & 0.26 & 0.44 & & & \\
\hline
\end{tabular}

Descriptive statistics based on 504 regular articles published in The Energy Journal between 1996 and 2013. See Section 2 and Table 1 for further details on variable construction. Summary statistics of 3, 5, and 10 year citation DVs and Author cites are reported before inverse hyperbolic sine transformation for interpretation purposes. Pairwise correlations are on the main dependent variable of 5-year Citations.

we see that including a colon in a title is also positively related to future citations. In the GETS modeling in Table 4 we find the presence of a question or colon in the title remains positive and significant in the reduced model. The elasticities analysis in the same table shows a $1.5 \%$ impact on citations from having a question mark and a $6.2 \%$ impact from using a colon.

Titles: Titles should be short, and if not short, would benefit from a colon to improve readability. Posing a question as a title is usually related to higher future citations.

\subsubsection{Abstracts}

Abstracts should clearly and concisely discuss the purpose of a study, the main findings, and key implications (Zimmerman, 1989). Weiss and Newman (2011) go as far as to specify a sentence-by-sentence structure that elaborates in more detail on this idea. In terms of technical structure, prior research shows that longer abstracts are generally related to higher citations (vanWesel, Wyatt and ten Haaf, 2014), perhaps due to providing more filtering information to researchers. Dowling, Hammami and Zreik (2018) finds that better readability of abstracts for Economics Letters journal articles is positively related to future citations.

Abstracts in our study are about 150 words long, with the tests in Table 3 showing a mild positive relationship between length and future citations. Readability complexity for abstracts, measured by the Gunning-Fog Index, has an average score of 15.5, and we don't find any significance for readability in the testing. However, this might be due to an interesting readability pattern shown in Figure 1 (bottom figure). Here we see that readability of abstracts has fallen from requiring a college graduate education to a college sophomore level over the sample period. It might be that 
Figure 2: Top figure: Average count of figures per article by publication year. Bottom figure: Occurrences of active voice per page of article (use of $w e$ ) by publication year.
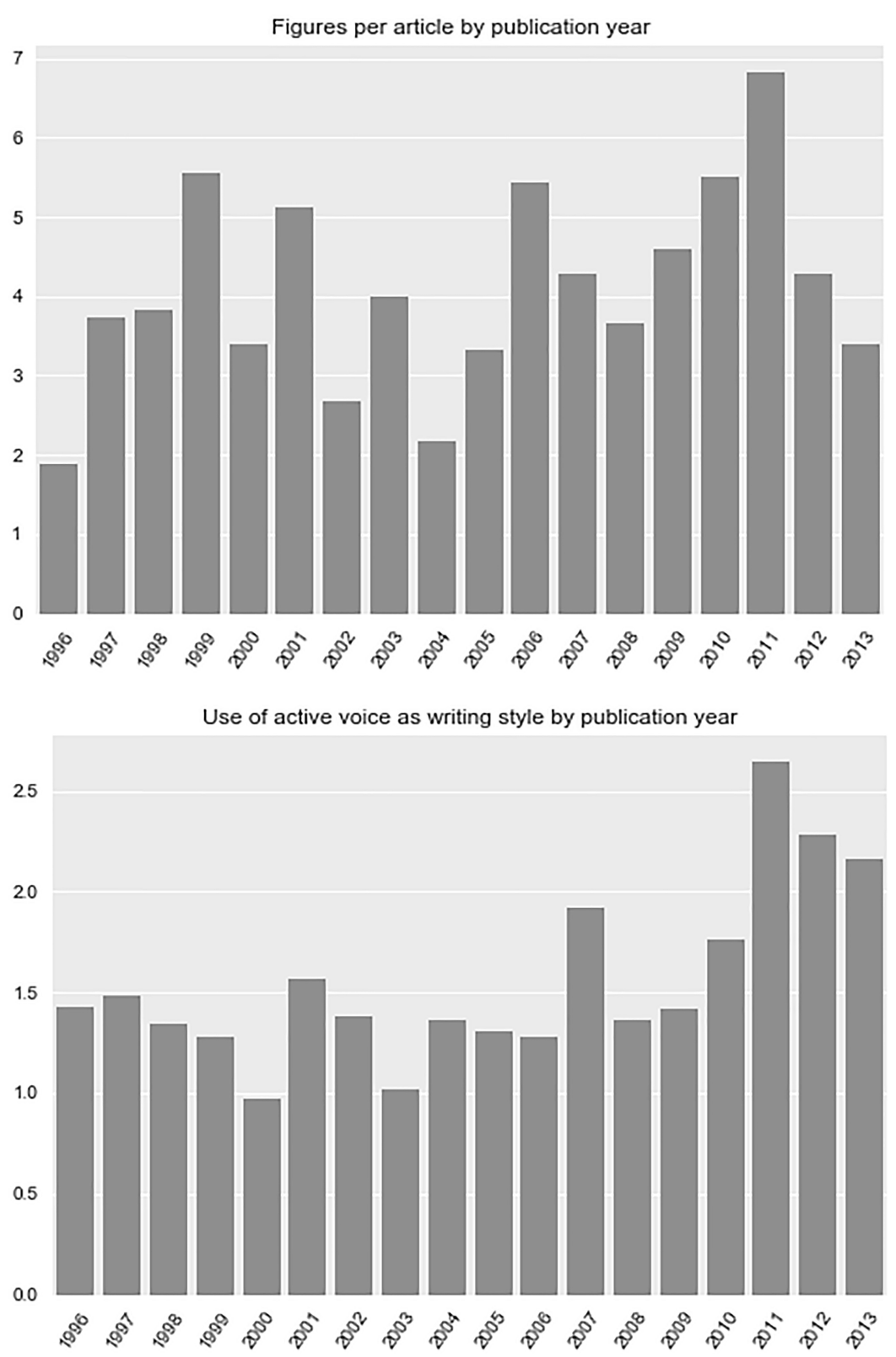

there has been greater emphasis placed on readability over time by journal editors, better training in appropriate writing style for authors, or perhaps that authors are more focused on reaching a wider audience in the presentation of their research. Good readability, therefore, does not particularly improve future citations but is instead a normal expectation.

Abstracts: Abstracts should be readable by a reasonably competent undergraduate student in energy economics. Length does not matter, but rather use the space needed, within the journal limitations, to clearly state the purpose, findings, and implications of your research. 
Figure 3: Top figure: Average article 5-year citations grouped by highest ranked author institution. Citations are raw citation counts. The unranked column includes both corresponding authors from universities not in ARWU Top 500 rank as well as industry authors. Bottom figure: regplot of researcher impact on 5-year citations. Researcher impact is average citations across all article authors' prior articles at time of publication. Both citation measures are after inverse hyperbolic sine (asinh) transformation.

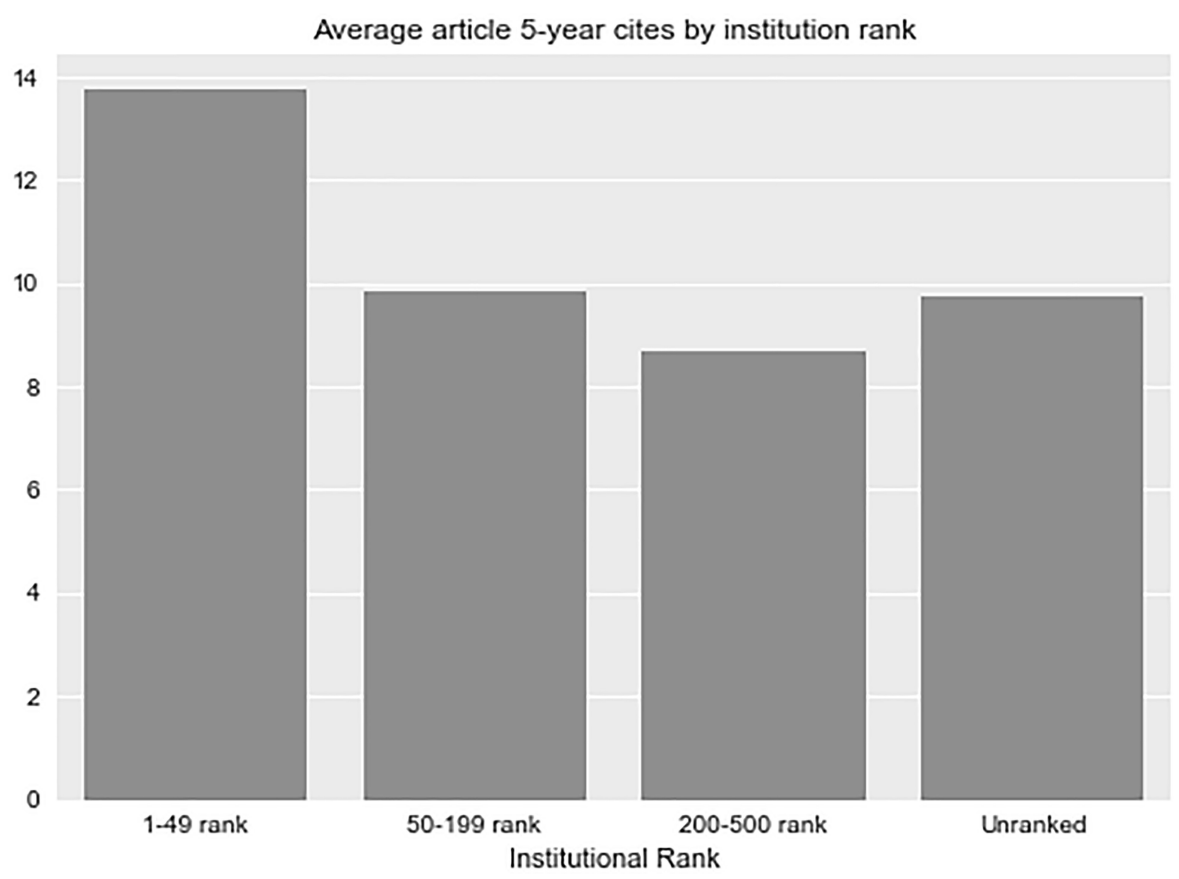

Regplot of the relationship between researcher impact and subsequent citations

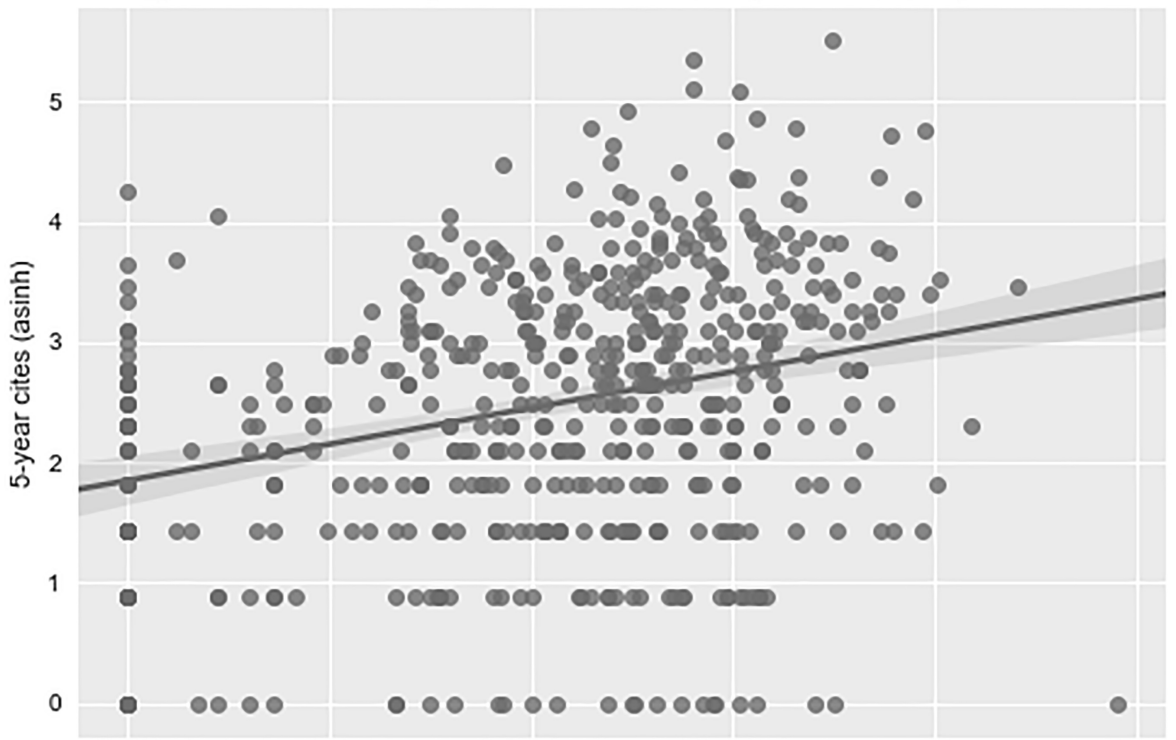

Researcher impact (asinh) 
Table 3: Energy economics research impact: Main results

\begin{tabular}{|c|c|c|c|c|c|c|}
\hline & \multicolumn{3}{|c|}{ Citations } & \multicolumn{3}{|c|}{ Top $25 \%$ most-cited } \\
\hline & 3-year & 5-year & 10-year & 3-year & 5-year & 10-year \\
\hline Topic_JEL & $\begin{array}{c}0.086 \\
(0.088)\end{array}$ & $\begin{array}{c}0.082 \\
(0.093)\end{array}$ & $\begin{array}{l}-0.096 \\
(0.127)\end{array}$ & $\begin{array}{l}-0.041 \\
(0.138)\end{array}$ & $\begin{array}{l}-0.003 \\
(0.140)\end{array}$ & $\begin{array}{c}-0.329^{*} \\
(0.179)\end{array}$ \\
\hline Title_Length & $\begin{array}{c}-0.023^{*} \\
(0.013)\end{array}$ & $\begin{array}{c}-0.030^{* *} \\
(0.014)\end{array}$ & $\begin{array}{c}-0.045^{* *} \\
(0.019)\end{array}$ & $\begin{array}{l}-0.023 \\
(0.021)\end{array}$ & $\begin{array}{l}-0.014 \\
(0.022)\end{array}$ & $\begin{array}{c}-0.058^{* *} \\
(0.028)\end{array}$ \\
\hline Title_Question & $\begin{array}{l}0.243^{*} \\
(0.132)\end{array}$ & $\begin{array}{c}0.304^{* *} \\
(0.140)\end{array}$ & $\begin{array}{c}0.182 \\
(0.186)\end{array}$ & $\begin{array}{c}0.488^{* *} \\
(0.199)\end{array}$ & $\begin{array}{c}0.277 \\
(0.201)\end{array}$ & $\begin{array}{c}0.163 \\
(0.256)\end{array}$ \\
\hline Title_Colon & $\begin{array}{c}0.289 * * * \\
(0.095)\end{array}$ & $\begin{array}{c}0.310^{* * * *} \\
(0.100)\end{array}$ & $\begin{array}{l}0.322 * * \\
(0.136)\end{array}$ & $\begin{array}{c}0.362 * * \\
(0.146)\end{array}$ & $\begin{array}{c}0.358^{* *} \\
(0.149)\end{array}$ & $\begin{array}{l}0.318^{*} \\
(0.191)\end{array}$ \\
\hline Abs_Length & $\begin{array}{c}0.001 \\
(0.001)\end{array}$ & $\begin{array}{l}0.002 * \\
(0.001)\end{array}$ & $\begin{array}{l}0.003^{*} \\
(0.002)\end{array}$ & $\begin{array}{c}0.001 \\
(0.002)\end{array}$ & $\begin{array}{l}-0.001 \\
(0.002)\end{array}$ & $\begin{array}{c}0.001 \\
(0.002)\end{array}$ \\
\hline Abs_Readability & $\begin{array}{l}-0.011 \\
(0.017)\end{array}$ & $\begin{array}{l}-0.020 \\
(0.018)\end{array}$ & $\begin{array}{l}-0.010 \\
(0.023)\end{array}$ & $\begin{array}{c}0.019 \\
(0.027)\end{array}$ & $\begin{array}{c}0.010 \\
(0.028)\end{array}$ & $\begin{array}{c}0.026 \\
(0.032)\end{array}$ \\
\hline Paper_Length & $\begin{array}{c}0.022 * * * \\
(0.007)\end{array}$ & $\begin{array}{c}0.024 * * * \\
(0.007)\end{array}$ & $\begin{array}{c}0.050 * * * \\
(0.011)\end{array}$ & $\begin{array}{c}0.023 * * \\
(0.011)\end{array}$ & $\begin{array}{l}0.019^{*} \\
(0.011)\end{array}$ & $\begin{array}{c}0.053 * * * \\
(0.015)\end{array}$ \\
\hline Paper_Readability & $\begin{array}{c}0.054 \\
(0.034)\end{array}$ & $\begin{array}{l}0.066^{*} \\
(0.036)\end{array}$ & $\begin{array}{c}0.018 \\
(0.047)\end{array}$ & $\begin{array}{l}-0.004 \\
(0.051)\end{array}$ & $\begin{array}{l}-0.046 \\
(0.051)\end{array}$ & $\begin{array}{l}-0.081 \\
(0.063)\end{array}$ \\
\hline Paper_Commas & $\begin{array}{l}-0.005 \\
(0.008)\end{array}$ & $\begin{array}{l}-0.002 \\
(0.008)\end{array}$ & $\begin{array}{c}0.001 \\
(0.011)\end{array}$ & $\begin{array}{c}0.001 \\
(0.012)\end{array}$ & $\begin{array}{c}0.009 \\
(0.012)\end{array}$ & $\begin{array}{c}0.005 \\
(0.015)\end{array}$ \\
\hline Paper_Active & $\begin{array}{c}0.047 \\
(0.036)\end{array}$ & $\begin{array}{c}0.036 \\
(0.038)\end{array}$ & $\begin{array}{c}0.058 \\
(0.056)\end{array}$ & $\begin{array}{c}0.071 \\
(0.054)\end{array}$ & $\begin{array}{c}0.088 \\
(0.055)\end{array}$ & $\begin{array}{l}0.133^{*} \\
(0.074)\end{array}$ \\
\hline Tables & $\begin{array}{c}0.061 \\
(0.122)\end{array}$ & $\begin{array}{c}0.092 \\
(0.129)\end{array}$ & $\begin{array}{c}0.095 \\
(0.166)\end{array}$ & $\begin{array}{l}-0.034 \\
(0.195)\end{array}$ & $\begin{array}{l}-0.110 \\
(0.195)\end{array}$ & $\begin{array}{c}0.133 \\
(0.240)\end{array}$ \\
\hline Figures & $\begin{array}{c}-0.008 \\
(0.098)\end{array}$ & $\begin{array}{l}-0.004 \\
(0.104)\end{array}$ & $\begin{array}{c}0.162 \\
(0.139)\end{array}$ & $\begin{array}{c}0.094 \\
(0.157)\end{array}$ & $\begin{array}{c}0.191 \\
(0.161)\end{array}$ & $\begin{array}{c}0.122 \\
(0.198)\end{array}$ \\
\hline Ref_Count & $\begin{array}{c}0.253^{* * *} * \\
(0.081)\end{array}$ & $\begin{array}{c}0.263 * * * \\
(0.085)\end{array}$ & $\begin{array}{c}0.318^{* * * *} \\
(0.120)\end{array}$ & $\begin{array}{c}0.140 \\
(0.125)\end{array}$ & $\begin{array}{c}0.001 \\
(0.130)\end{array}$ & $\begin{array}{c}0.182 \\
(0.174)\end{array}$ \\
\hline Ref_Recent & $\begin{array}{c}1.113^{* * *} * \\
(0.204)\end{array}$ & $\begin{array}{c}1.053 * * * \\
(0.216)\end{array}$ & $\begin{array}{c}0.640 * * \\
(0.288)\end{array}$ & $\begin{array}{c}1.376 * * * \\
(0.334)\end{array}$ & $\begin{array}{c}1.314 * * * \\
(0.343)\end{array}$ & $\begin{array}{l}0.773^{*} \\
(0.419)\end{array}$ \\
\hline Ref_Peer & $\begin{array}{c}0.290 \\
(0.282)\end{array}$ & $\begin{array}{l}0.573 * \\
(0.298)\end{array}$ & $\begin{array}{l}0.996 * * \\
(0.410)\end{array}$ & $\begin{array}{c}0.518 \\
(0.449)\end{array}$ & $\begin{array}{l}0.851^{*} \\
(0.453)\end{array}$ & $\begin{array}{c}0.771 \\
(0.598)\end{array}$ \\
\hline Author_Count & $\begin{array}{l}0.073 * \\
(0.037)\end{array}$ & $\begin{array}{l}0.070 * \\
(0.039)\end{array}$ & $\begin{array}{c}0.066 \\
(0.066)\end{array}$ & $\begin{array}{c}0.073 \\
(0.061)\end{array}$ & $\begin{array}{c}0.099 \\
(0.063)\end{array}$ & $\begin{array}{c}0.077 \\
(0.086)\end{array}$ \\
\hline Author_Cites & $\begin{array}{c}0.056^{* *} \\
(0.024)\end{array}$ & $\begin{array}{c}0.073 * * * \\
(0.025)\end{array}$ & $\begin{array}{c}0.083 * * \\
(0.035)\end{array}$ & $\begin{array}{c}0.123 * * * \\
(0.039)\end{array}$ & $\begin{array}{c}0.156^{* * *} \\
(0.041)\end{array}$ & $\begin{array}{c}0.132 * * \\
(0.051)\end{array}$ \\
\hline Author_RankInstit: & & & & & & \\
\hline : Unranked & $\begin{array}{c}-0.209 * \\
(0.126)\end{array}$ & $\begin{array}{c}-0.260^{*} \\
(0.133)\end{array}$ & $\begin{array}{c}-0.358^{*} \\
(0.186)\end{array}$ & $\begin{array}{c}-0.362 * \\
(0.205)\end{array}$ & $\begin{array}{l}-0.271 \\
(0.208)\end{array}$ & $\begin{array}{c}-0.757 * * \\
(0.308)\end{array}$ \\
\hline$: 50-<200$ th & $\begin{array}{c}-0.286^{* *} \\
(0.122)\end{array}$ & $\begin{array}{l}-0.180 \\
(0.129)\end{array}$ & $\begin{array}{l}-0.269 \\
(0.182)\end{array}$ & $\begin{array}{c}-0.546 * * * \\
(0.196)\end{array}$ & $\begin{array}{c}-0.417 * * \\
(0.197)\end{array}$ & $\begin{array}{l}-0.381 \\
(0.251)\end{array}$ \\
\hline$: 1-<50$ th & $\begin{array}{l}-0.015 \\
(0.118)\end{array}$ & $\begin{array}{c}0.045 \\
(0.125)\end{array}$ & $\begin{array}{c}-0.023 \\
(0.168)\end{array}$ & $\begin{array}{l}-0.090 \\
(0.176)\end{array}$ & $\begin{array}{l}-0.017 \\
(0.177)\end{array}$ & $\begin{array}{l}-0.196 \\
(0.222)\end{array}$ \\
\hline Periods & $\begin{array}{c}0.502 * * * \\
(0.112)\end{array}$ & $\begin{array}{c}0.433 * * * \\
(0.118)\end{array}$ & $\begin{array}{c}0.446 * * * \\
(0.153)\end{array}$ & $\begin{array}{c}0.698 * * * \\
(0.194)\end{array}$ & $\begin{array}{c}0.741 * * * \\
(0.201)\end{array}$ & $\begin{array}{c}0.711 * * * \\
(0.222)\end{array}$ \\
\hline Constant & $\begin{array}{l}-0.824 \\
(0.570)\end{array}$ & $\begin{array}{l}-0.543 \\
(0.602)\end{array}$ & $\begin{array}{c}0.219 \\
(0.773)\end{array}$ & $\begin{array}{c}-3.681 * * * \\
(0.932)\end{array}$ & $\begin{array}{c}-3.255^{* * *} \\
(0.930)\end{array}$ & $\begin{array}{c}-2.925 * * * \\
(1.115)\end{array}$ \\
\hline Number of articles & 504.000 & 504.000 & 328.000 & 504.000 & 504.000 & 328.000 \\
\hline F-stat / Chi-square & $7.57 * * *$ & $7.50 * * *$ & $5.11 * * *$ & $94.58 * * *$ & $96.26^{* * *}$ & $74.85 * * *$ \\
\hline Adj / Pseudo R-square & 0.215 & 0.213 & 0.209 & 0.162 & 0.169 & 0.201 \\
\hline
\end{tabular}

Table reports findings from OLS regressions (Citations) and probit regressions (Top 25\% most-cited) on three-, five-, and ten-year subsequent citations to articles published in The Energy Journal from 1996-2013 (1996-2008 for ten-year citations). For the main citations dependent variables citation counts have been transformed using an inverse hyperbolic sine function to account for skewness. See Section 2 and Table 1 for further details on variable construction and testing approach. Contrast Author RankInstit category are articles where the top ranked institution of the authors is 200-500th. $* p<0.10, * * p<0.05, * * * p<0.01$, standard error in brackets. 
Table 4: Energy economics research impact: GETS modeling and elasticities

\begin{tabular}{|c|c|c|c|c|c|c|}
\hline & \multicolumn{3}{|c|}{ General-to-specific model } & \multicolumn{3}{|c|}{ Elasticities } \\
\hline & 3-year & 5-year & 10-year & 3-year & 5-year & 10-year \\
\hline Title_Question & & $\begin{array}{c}0.348^{* *} \\
(0.135)\end{array}$ & & & $\begin{array}{c}0.015^{* *} \\
(0.007)\end{array}$ & \\
\hline Title_Colon & $\begin{array}{c}0.240 * * * \\
(0.086)\end{array}$ & & & $\begin{array}{c}0.062 * * * \\
(0.020)\end{array}$ & & \\
\hline Paper_Length & $\begin{array}{c}0.023 * * * \\
(0.006)\end{array}$ & $\begin{array}{c}0.027 * * * \\
(0.006)\end{array}$ & $\begin{array}{c}0.051^{* * * *} \\
(0.009)\end{array}$ & $\begin{array}{c}0.266 * * * \\
(0.083)\end{array}$ & $\begin{array}{c}0.214 * * * \\
(0.065)\end{array}$ & $\begin{array}{c}0.340 * * * \\
(0.071)\end{array}$ \\
\hline Ref_Count & $\begin{array}{c}0.190 * * * \\
(0.070)\end{array}$ & & & $\begin{array}{c}0.181 * * * \\
(0.058)\end{array}$ & & \\
\hline Ref_Recent & $\begin{array}{c}1.145^{* * *} * \\
(0.194)\end{array}$ & $\begin{array}{c}0.966 * * * \\
(0.200)\end{array}$ & $\begin{array}{c}0.549 * * \\
(0.257)\end{array}$ & $\begin{array}{c}0.275 * * * \\
(0.051)\end{array}$ & $\begin{array}{c}0.192 * * * \\
(0.040)\end{array}$ & $\begin{array}{c}0.091 * * \\
(0.041)\end{array}$ \\
\hline Ref_Peer & & $\begin{array}{c}0.679 * * \\
(0.290)\end{array}$ & $\begin{array}{c}0.910^{* *} \\
(0.380)\end{array}$ & & $\begin{array}{l}0.059^{*} \\
(0.030)\end{array}$ & $\begin{array}{c}0.078 * * \\
(0.032)\end{array}$ \\
\hline Author_Count & & $\begin{array}{c}0.081 * * \\
(0.036)\end{array}$ & & & $\begin{array}{c}0.060^{*} \\
(0.033)\end{array}$ & \\
\hline Author_Cites & $\begin{array}{c}0.056^{* *} \\
(0.022)\end{array}$ & $\begin{array}{c}0.095 * * * \\
(0.023)\end{array}$ & $\begin{array}{c}0.110^{* * * *} \\
(0.031)\end{array}$ & $\begin{array}{c}0.131 * * \\
(0.056)\end{array}$ & $\begin{array}{c}0.127 * * * \\
(0.044)\end{array}$ & $\begin{array}{c}0.106 * * \\
(0.045)\end{array}$ \\
\hline Periods & $\begin{array}{c}0.564 * * * \\
(0.101)\end{array}$ & $\begin{array}{c}0.576 * * * \\
(0.098)\end{array}$ & $\begin{array}{c}0.667 * * * \\
(0.125)\end{array}$ & & & \\
\hline Constant & $\begin{array}{l}-0.290 \\
(0.227)\end{array}$ & $\begin{array}{c}0.250 \\
(0.225)\end{array}$ & $\begin{array}{c}0.811 * * * \\
(0.289)\end{array}$ & & & \\
\hline Number of articles & 514 & 539 & 362 & & & \\
\hline F-stat & $18.92 * * *$ & $19.86^{* * *}$ & $18.92 * * *$ & & & \\
\hline Adj R-square & 0.197 & 0.197 & 0.199 & & & \\
\hline
\end{tabular}

Table reports findings from general-to-specific (GETS) modeling of full model reported in Table 3 on three-, five-, and ten-year subsequent citations to articles published in The Energy Journal from 1996-2013 (1996-2008 for ten-year citations). Also reported are elasticities for significant variables as identified by the GETS modeling. See Section 2 and Table 1 for further details on variable construction and testing approach. * $p<0.10, * * p<0.05, * * * p<0.01$, standard error in brackets.

\subsection{Full article}

For the full article, the most important characteristics include the length and readability complexity. Other writing style characteristics, such as the use of commas (an alternative proxy to the Gunning-Fog Index for sentence construction complexity), and the use of an active rather than a passive writing style, appear to have some weaker effects. We also include measures of the numbers of tables and figures and three assessments of the referencing used to justify arguments in the article.

\subsubsection{Article structure}

Longer articles generate more citations (Falagas et al., 2013), perhaps because of the greater information content of longer articles (Leimu and Koricheva, 2005). Articles with greater theoretical contributions tend to be more cited over time (Colquitt and Zapata-Phelan, 2007) compared to those with a stronger emphasis on empirics. A rationale for this is that theoretical research often leads to calls for empirical testing of the theory, with repeated empirical studies required to assess the validity of the theory. Other recommendations are that articles include figures or charts as an explanatory aid to comprehension. Clark and Divvala (2016) find a large upward trend in the use of figures over time, but only a weak correlation with citations.

Our testing shows the length of articles to be particularly important. Length is positively related to citations in all main tests and remains significant in the GETS reduced-form model. The elasticities analysis shows the practical significance of the measures. We don't find a significant re- 
lationship for our proxy for empirical or theory articles: the presence of tables in a paper. This might be because nearly all articles (85\%) have at least two tables and, therefore, nearly all articles are empirical based on this measure. Figures are also widely used in The Energy Journal articles, with about $70 \%$ of articles containing two or more figures. The testing finds these to be insignificantly related to citations. However, we do see a compelling upward trend in Figure 2 (top figure) when we chart the use of figures over time. There is approximately one extra figure per article in the second half of the sample compared to the first. About four figures per paper is the current average, albeit that this is driven, in part, by a relatively small number of articles with a large number of figures.

Article structure: Articles should aim to use all the space needed when writing articles (up to 9,500 words according to current journal policy). Although this does not preclude the important need to avoid irrelevant details and unnecessary verbosity. Nearly all articles have tables, and the use of visual guides in the form of figures, three to five figures normally, is an expectation rather than an advantage.

\subsubsection{Writing style}

Improving writing style in economics is at the heart of the influential work of McCloskey (2019). The breadth of this advice is beyond the space available here but, in summary, says: write clearly, with the reader in mind. We should aim to tell the reader what they need to know in a way that they will understand. Some specific advice frequently proffered is to write in the active rather than the passive voice and reduce the use of commas, with commas being a proxy for sentence complexity. The modern recommendation to use personal pronouns ('I,' 'we') in writing is often linked to the recommendation to use the active voice, although not by definition (Banks, 2017).

We test the importance of these writing recommendations. Tests include overall readability and per page counts of the use of commas and the most common personal pronoun- 'we'. The tests do not show a compelling, significant link between any of the measures and citations. One reason for this might be, similar to other variables already discussed, that there has been a trend over time in favor of reducing readability complexity and increasing the use of personal pronouns. We see that for the personal pronoun in Figure 2 (bottom figure) where the most recent years have seen a large rise in usage.

Writing style: Our technical tests are no substitute for the excellent writing advice in McCloskey (2019). We do however note that personal pronouns are now the expectation in writing, as is aiming article writing complexity at "the least sophisticated rather than the most sophisticated reader" of a journal (Zimmerman, 1989) (p. 460).

\subsubsection{References}

References in an article are used to support arguments, justify choices, and compare findings (Swales, 1986). Leydesdorff, Bornmann and Wagner (2017) provides comprehensive charts showing this clustering at the journal level. Articles can, therefore, indicate membership of a field by selecting references from among clustered journals. Roth, Wu and Lozano (2012) shows the importance of peer journal referencing in their cross-disciplinary study on drivers of article citation. They also show the importance of references being recent in terms of publication time proximity to the article. 
Our testing includes a count of references (scaled by article length), the proportion of references from the last five years, and the proportion of references that belong to a cluster of peer journals. On average, the articles in the sample cite 30 references, with about half from the most recent five years, and a quarter drawn from peer journals. Both the measures of recency and peer journal citation are quite stable over time, albeit with a small uptrend in citing from among peer journals. The (unreported) proportion of citations to prior The Energy Journal articles is rising over time, from around 1.5 citations per article in the early sample period to above two citations per article in recent times. The results from the main testing and the GETS modeling shows a strong positive significance for articles with more references, and articles citing a higher proportion of recent articles. We also see some significance for the proportion of peer journal citations in longer citation windows.

References: It is better to have more than fewer references in support of article argumentation, but without running the risk of 'argument by citation' (Sparrowe and Mayer, 2011) as it weakens researcher authority and affects readability. References should come from the most recent five years, with a reasonable proportion from peer journals to build relevant arguments of interest to target readers.

\subsection{Author characteristics}

The last group of factors is related to the authors themselves. Prior research shows higher author past citations and institutional affiliation to be linked to higher article citation (Hurley, Ogier and Torvik, 2013; Amara, Landry and Halilem, 2015). This is quite intuitive as both measures speak to the a priori ability of authors to generate impact from their research. The measures are, at a broad level, related to each other in that institutional rankings often incorporate combined citations to their faculty in the ranking process (Lin, Huang and Chen, 2013). Articles with more authors are also linked to higher citations (Thelwall and Sud, 2016), perhaps due to the benefits of collaboration in producing quality research.

The average article in our sample has two authors, of which the averaged prior citations per author is 164 but with a large standard deviation of three times the mean. Twenty-six percent of best-ranked authors come from an institution ranked in the global top 50, perhaps reflective of the high ranking of the journal. Thirty-eight percent of best-ranked authors are from outside the global top 500 academic institutions, including a large proportion of industry and policymaker researchers. Exploratory analysis in Figure 3 (top figure) shows that most citations are to articles where the best-ranked author is from a top 50 institution. However there is also a strong citation impact from articles in the unranked group suggesting the benefit of the diverse author backgrounds encouraged by the journal. We also see in Figure 3 (bottom figure) a positive relationship between prior author citations and article citations. The formal tests in Table 3 show some statistical significance for the number of authors and strong significance for author prior citations. Institutional rank provides mixed results.

Author characteristics: Multiple author articles are the norm, perhaps because of the research benefits of collaboration. The depth of research experience of the author group is important; a group that includes an author who has strong prior citations tends to benefit significantly from their experience. 


\section{DISCUSSION}

We have explored, for the first time, determinants of energy economics research impact. We concentrate on how non-topic writing and structural features of articles influence subsequent citations. Our findings are perhaps surprising, in that about $20 \%$ of the variation in future citations to The Energy Journal articles can be explained by these factors. By blending our statistical analysis with existing advice on good writing in economics and energy science, we can offer a condensed set of guidelines for creating impact.

This study thus propounds the strong benefits of paying attention not just to the topic of an article, but also to how it is written, presented, and structured. It is, however, worth bearing in mind when interpreting these findings that we have, by necessity, only measured impact by future citations. Future research, when feasible, could explore influences on a wider meaning of impact. Perhaps a viable approach to this could be through qualitative analysis of impact reports submitted by researchers to national research evaluation frameworks (such as the UK REF).

\section{ACKNOWLEDGMENTS}

We benefited significantly from an excellent and thorough reviewing process, and wish to acknowledge and thank the reviewers for their transformational impact on the structure, style, and meaning, of the final article.

\section{REFERENCES}

Bailin, A. and A. Grafstein (2016). Readability: Text and Context. Springer, New York. https://doi.org/10.1057/ 9781137388773.

Banks, D. (2017). "The extent to which the passive voice is used in the scientific journal article, 1985-2015." Functional Linguistics 4(1): 12. https://doi.org/10.1186/s40554-017-0045-5.

Campos, J., N.R. Ericsson and D.F. Hendry (2005). "General-to-specific modeling: An overview and selected bibliography." FRB International Finance Discussion Paper. https://doi.org/10.17016/IFDP.2005.838.

Card, D. and S. DellaVigna (2017). "What do editors maximize? Evidence from four leading economics journals." National Bureau of Economic Research, w23282. https://doi.org/10.3386/w23282.

Clark, C. and S. Divvala (2016). "Pdffigures 2.0: Mining figures from research papers." 2016 IEEE/ACM Joint Conference on Digital Libraries (JCDL) 143-152. https://doi.org/10.1145/2910896.2910904.

Clarke, D. (2014). "General-to-specific modeling in Stata." The Stata Journal 14(4): 895-908. https://doi.org/10.1177/ $1536867 X 1401400412$.

Colquitt, J.A. and C.P. Zapata-Phelan (2007). "Trends in theory building and theory testing: A five-decade study of the Academy of Management Journal." Academy of Management Journal 50(6): 1281-1303. https://doi.org/10.5465/amj. 2007.28165855.

Costello, M.J., K.H. Beard, R.B. Primack, V. Devictor, and A.E. Bates (2019). “Are killer bees good for coffee? The contribution of a paper's title and other factors to its future citations." Biological Conservation 229: A1-A5. https://doi. org/10.1016/j.biocon.2018.07.010.

Dowling, M., H. Hammami, and O. Zreik (2018). "Easy to read, easy to cite?” Economics Letters 173: 100-103. https://doi. org/10.1016/j.econlet.2018.09.023.

Falagas, M.E., A. Zarkali, D.E. Karageorgopoulos, V. Bardakas, and M.N. Mavros (2013). "The impact of article length on the number of future citations: A bibliometric analysis of general medicine journals." PLoS One 8(2): e49476. https://doi. org/10.1371/journal.pone.0049476.

Hansen, B.E. (1996). “Methodology: Alchemy or Science?” Economic Journal 106(438): 1398-1413. https://doi.org/10. $2307 / 2235531$.

Hudson, J. (2016). "An analysis of the titles of papers submitted to the UK REF in 2014: Authors, disciplines, and stylistic details.” Scientometrics 109(2): 871-889. https://doi.org/10.1007/s11192-016-2081-4. 
Hurley, L.A., A.L. Ogier, and V.I. Torvik (2013). "Deconstructing the collaborative impact: Article and author characteristics that influence citation count." Proceedings of the 76th ASIS\&T Annual Meeting: Beyond the Cloud: Rethinking Information Boundaries. https://doi.org/10.1002/meet.14505001070.

Hurley, L.A., A.L. Ogier, and V.I. Torvik (2015). "What can university administrators do to increase the publication and citation scores of their faculty members?” Scientometrics 103(2): 489-530. https://doi.org/10.1007/s11192-015-1537-2.

Jamali, H.R. and M. Nikzad (2011). "Article title type and its relation with the number of downloads and citations." Scientometrics 88(2): 653-661. https://doi.org/10.1007/s11192-011-0412-z.

Leimu, R. and J. Koricheva (2005). "What determines the citation frequency of ecological papers?" Trends in Ecology \& Evolution 20(1): 28-32. https://doi.org/10.1016/j.tree.2004.10.010.

Leydesdorff, L., L. Bornmann, and C.S. Wagner (2017). "Generating clustered journal maps: An automated system for hierarchical classification.” Scientometrics 110(3): 1601-1614. https://doi.org/10.1007/s11192-016-2226-5.

Li, E.Y., C.H. Liao and H.R. Yen (2013). "Co-authorship networks and research impact: A social capital perspective.” Research Policy 42(9): 1515-1530. https://doi.org/10.1016/j.respol.2013.06.012.

Lin, C.-S., M.-H. Huang, and D.-Z. Chen (2013). “The influences of counting methods on university rankings based on paper count and citation count." Journal of Informetrics 7(3): 611-621. https://doi.org/10.1016/j.joi.2013.03.007.

McCloskey, D. (1985). “Economical writing.” Economic Inquiry 23(2): 187-222. https://doi.org/10.1111/j.1465-7295.1985. tb01761.x.

McCloskey, D. (2019). Economical Writing. University of Chicago Press, Chicago (3rd edition).

Penfield, T., M.J. Baker, R. Scoble and m. C. Wykes (2014). “Assessment, evaluations, and definitions of research impact: A review.” Research Evaluation 23(1): 21-32. https://doi.org/10.1093/reseval/rvt021.

Reinstein, A., J.R. Hasselback, M.E. Riley and D.H. Sinason (2011). "Pitfalls of using citation indices for making academic accounting promotion, tenure, teaching load, and merit pay decisions." Issues in Accounting Education 26(1): 99-131. https://doi.org/10.2308/iace.2011.26.1.99.

Roth, C., J. Wu, and S. Lozano (2012). “Assessing impact and quality from local dynamics of citation networks.” Journal of Informetrics 6(1): 111-120. https://doi.org/10.1016/j.joi.2011.08.005.

Sparrowe, R.T. and K.J. Mayer (2011). "Publishing in AMJ-part 4: Grounding hypotheses." Academy of Management Journal 54(6): 1098-1102. https://doi.org/10.5465/amj.2011.4001.

Swales, J. (1986). "Citation analysis and discourse analysis." Applied Linguistics 7(1): 39-56. https://doi.org/10.1093/ applin/7.1.39.

Tahamtan, I., A.S. Afshar and K. Ahamdzadeh (2016). "Factors affecting number of citations: A comprehensive review of the literature." Scientometrics 107(3): 1195-1225. https://doi.org/10.1007/s11192-016-1889-2.

Thelwall, M. and P. Sud (2016). "National, disciplinary and temporal variations in the extent to which articles with more authors have more impact: Evidence from a geometric field normalised citation indicator." Journal of Informetrics 10(1): 48-61. https://doi.org/10.1016/j.joi.2015.11.007.

van Wesel, M., S. Wyatt and J. ten Haaf (2014). "What a difference a colon makes: How superficial factors influence subsequent citation.” Scientometrics 98(3): 1601-1615. https://doi.org/10.1007/s11192-013-1154-x.

Walker, T.C. (2010). "The perils of paradigm mentalities: Revisiting Kuhn, Lakatos, and Popper.” Perspectives on Politics 8(2): 433-451. https://doi.org/10.1017/S1537592710001180.

Weiss, M. and A.M. Newman (2011). “A guide to writing articles in energy science.” Applied Energy 88(11): 3941-3948. https://doi.org/10.1016/j.apenergy.2011.04.007.

Zimmerman, J.L. (1989). "Improving a manuscript's readability and likelihood of publication." Issues in Accounting Education 4(2): 458-466. 


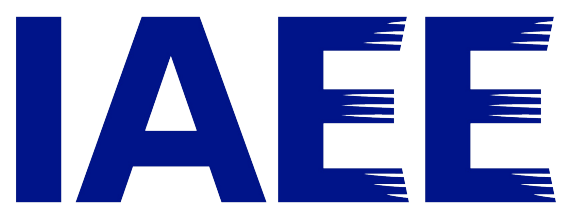

\section{International Association for ENERGY ECONOMICS}

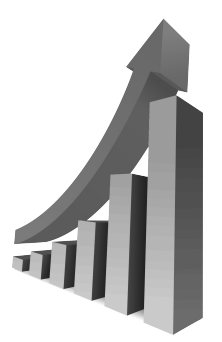

The IAEE is pleased to announce that our leading publications exhibited strong performances in the latest 2019 Impact Factors as reported by Clarivate. The Energy Journal achieved an Impact Factor of 2.394 while Economics of Energy \& Environmental Policy saw an increase to 3.217.

Both publications have earned SCIMago Journal Ratings in the top quartile for Economics and Econometrics publications.

IAEE wishes to congratulate and thank all those involved including authors, editors, peer-reviewers, the editorial boards of both publications, and to you, our readers and researchers, for your invaluable contributions in making 2019 a strong year. We count on your continued support and future submission of papers to these leading publications. 